Article

\title{
The Influence of Multi-Dimensional Cognition on the Formation of the Sense of Place in an Urban Riverfront Space
}

\author{
Ling-Qing Zhang ${ }^{1,2,3}$, Wei Deng ${ }^{1,2, *}$, Jing Yan ${ }^{3, *}$ and Xiao-Hong Tang ${ }^{3}$ \\ 1 Research Center for Mountain Development, Institute of Mountain Hazards and Environment, \\ Chinese Academy of Sciences, Chengdu 610041, China; 41360@sicau.edu.cn \\ 2 School of Resources and Environment, University of Chinese Academy of Sciences, Beijing 100049, China \\ 3 School of Architecture and Urban-Rural Planning, Sichuan Agricultural University, Du Jiangyan, \\ Chengdu 611830, China; 41344@sicau.edu.cn \\ * Correspondence: dengwei@imde.ac.cn (W.D.); 41357@sicau.edu.cn (J.Y.); \\ Tel.: +86-28-85353897 (W.D.); +86-13648069427 (J.Y.)
}

Received: 29 September 2019; Accepted: 18 December 2019; Published: 24 December 2019

\begin{abstract}
Urban riverfront spaces and associated riverine landscapes play important roles in promoting human-river interactions and shaping the regional characteristics of a city. This paper explored the urban riverfront space from the material level of the riverine landscape to a multi-dimensional cognitive level and constructed a theoretical exploration model of the influence of three cognitive dimensions (sensual cognition, intellectual cognition, and rational cognition) on the 'sense of place' (SOP) in urban riverfronts. In addition, the measurement scales for different cognitive dimensions were explored and designed. The structural equation model (SEM) was used to analyse 329 valid survey questionnaires in June 2019 in Dujiangyan Yihu Park, China. The analysis of the case study results showed that the overall theoretical model had a good model fit. The sensual cognition, intellectual cognition, and rational cognition all had a significant influence on the SOP in the riverfront park, of which the intellectual cognition had the most significant influence. Strengthening the creation of a riverine landscape for intellectual cognition is expected to enhance the SOP in riverfront spaces more effectively and achieve more enriched interactions between people and rivers.
\end{abstract}

Keywords: urban riverfront space; riverine landscape; cognitive dimensions; sense of place; structural equation model

\section{Introduction}

Rivers play an important role in human health and socio-economic development and are often influenced by both natural factors and human activities [1]. As human abilities to transform nature continue to grow, the impact of human activities on the sustainable development of rivers is becoming increasingly significant. Therefore, the interaction between people and rivers has become an important subject. The interaction between people and rivers in cities often takes place in the riverfront space with the riverside park as its core. This type of riverfront space often possesses both natural and human attributes and is featured by a rich riverine landscape. It has become important to improve the urban ecological environment, create ecological green corridors of urban landscapes, and provide citizens with good outdoor spaces for social interaction. Therefore, the focus of this study was the urban riverine landscape, which is a riverfront space beside a river within the city. The urban riverfront includes both natural and artificial visual landscapes, as well as cultural representations.

Many scholars have conducted detailed research on urban riverfront spaces. Sheng et al. [2] believed that the riverine landscape is a valuable resource of a city that influences urban styles and 
enhances the aesthetic urban environment. The authors of that study planned a riverfront tourism park on the banks of the Ili River in Xinjiang Uygur Autonomous Region in China, which integrated the elements of tourism, vacation and leisure, cultural display, and ecological protection. This was achieved through the division of the overall spatial structure, which was supplemented by ecological and scientific greening, and other special design techniques, such as revetment, and a construction plan relevant for a riverine landscape was outlined. Yin and Yang [3] further proposed that simplified riverine landscape planning and design are of little significance, and it is necessary to integrate the river ecological landscape planning with urban planning. Qiao et al. [4] proposed the synergetic development assessment (SDA) as a method for assessing the environmental, economic, and social performance of urban river system landscapes from the perspective of sustainable management. From a cultural viewpoint, Lu et al. [5] provided strategies that represented the regional culture to meet the requirements of sustainable design and development for the riverine landscape in small towns, and to promote the integration of function and landscaping.

Although we are constantly improving the research and construction of urban riverfront spaces, the number of rivers (urban streams not included) is gradually decreasing as a result of city development. According to the First National Water Census Bulletin published by The Ministry of Water Resources and the National Bureau of Statistics, the number of rivers with a drainage area of more than $100 \mathrm{~km}^{2}$ in China has reduced by more than half from previous statistics; however, it is difficult to determine the reduction of small rivers and lakes in various cities. In urban areas, the direct connection between people and rivers is gradually reducing. Thus, well-built riverfront parks can only serve as a limited solution. Through communication with residents of the older generation, we have observed that rivers are not located as close to people as they once were. As well as there being fewer rivers and lakes, economic development has reduced river water quality, and the interaction between people and rivers has gradually reduced due to ecological protection measures. Consequently, people have fewer opportunities to visit rivers and lakes and, ultimately, they can only indirectly perceive water through the increasingly rich riverine landscape.

The existing research on urban riverfront spaces mostly focuses on the improvement of the existing water ecology or the enhancement of the visual landscape [6]. However, such studies lack theoretical research on people's cognition of riverine landscapes and lack an in-depth understanding of how riverine landscapes affect people's sense of place (SOP) in the riverfront space. However, the formation of the SOP is one of the most important results of human-river interaction. A good SOP can better promote people's protection of rivers, rational development of rivers, and better use of rivers to enhance their well-being. Therefore, Davenport [7] built a complete network of river meanings through in-depth interviews. Kim and Moohan [8] studied the relationship between different ranges of perceived space of the rivers and the restoration effect of the environment. Kelly and Deborah [9] studied the level of specialisation among white-water recreationalists and their attachment to a popular white-water recreation river in the United States. Verbrugge [10] compared different methods for mapping the SOP in the riverine landscape and subsequently addressed how these studies provided information to the participatory process. However, these studies did not further explore the issue of cognitive dimensions.

Therefore, the present study focused on the interaction between people and rivers from the multi-cognitive dimension of the riverine landscape in an urban riverfront space. The mechanism of sustainable development between people and rivers was discussed through the perception of the riverine landscape, multi-dimensional cognition, and the formation of the SOP. Through these analyses, we can better understand the relationship between rivers and human activities from the perspective of people's multi-dimensional cognition based on the riverine landscape.

This study investigated whether people's cognition of riverine landscapes from different dimensions (sensual cognition, intellectual cognition, and rational cognition) was related to people's SOP. The study aimed to identify how the riverine landscape could be improved to further enhance our SOP of the riverfront space and promote enriched interactions between people and rivers. 


\section{Research Method}

Given the above questions, this study further refined the cognitive dimensions based on previous studies and constructed a structural equation model (SEM) of the relationship between three cognitive dimensions (sensual cognition, intellectual cognition, and rational cognition) and the SOP. In addition, according to relevant cognitive theories, the operational definitions of the three cognitive dimensions were redefined, and the measurement scales adapted to the Chinese environment were cited and self-developed for questionnaires. Finally, the theoretical model was empirically analysed by the SEM using Amos 24.0 software to obtain correlation verification using quantitative statistics.

\subsection{Construction of the Theoretical Model}

Modern philosophical research shows that the world is under our perceptual logic; our perceptual connection with the outside world is not in a vacuum but is governed by its transcendental logic and acquired culture. Kant [11] explored pure sensibility, intellectuality. and rationality in his book Critique of Pure Reason, arguing that human perception is not a vacuum. He proposed a transcendental theory: in addition to external information stimulation, human perception itself was innately pre-defined.

In Wang Dongyue's article General Theory of Material Evolution [12], human perceptual activities were divided into four levels: induction, sensibility, intellectuality, and rationality. However, he believed that it was difficult to separate pure intellectuality from the other activities because they were mutually influential. Hawking [13] also suggested in The Great Design that human knowledge was nothing more than "model-dependent realism", which relied on the perceptual model and the ideological model.

According to modern cognitive neuroscience research, the process of people's perception of the world is quite different due to biological differences in individuals, especially in the nervous system and cultural aspects. For example, some people have a sharp vision and can perceive more colours, while others are colour-blind and have difficulty distinguishing different colours. Some people are accustomed to perceptual thinking and are good at grasping the overall characteristics of things. Others are accustomed to rational thinking and are good at conducting analyses by using logical reasoning. This difference in perception often leads to differences in people's perceptions of the world, resulting in different attitudes. Among them, inductive cognition is a biologically-based induction process that is not controlled by explicit consciousness. For example, if the eye senses light of different spectra, it automatically converts it into an electrical signal that travels to the brain through the cone cells, and the brain converts the signal into different colours and visual images [14]. Sensual cognition is the sensory cognition of dependent objects by the brain, such as eyes seeing an image, ears hearing a sound, and the feeling of satisfaction from seeing food. Intellectual cognition is the distinction between multiple objects, such as distinguishing which fruits on the tree can be eaten, and where it is safe to live. However, the above examples are specific responses to the external environment. With regard to rational cognition, people can dispense with the specific constraints of the environment and recognise a broader world through an association and abstract logic analysis. For example, upon seeing a monument, one can associate it with the poignant stories that happened in the city. Or when noticing a falling apple, one can make an analysis and reasoning of the concept of gravity. In the process of biological evolution, these four ways of perception were gradually formed. However, when the rational iteration of people occurs, the intellectual, sensual, and inductive cognition are not pure; they are mutually influential. The more rational the cognition is, the greater the characterisation of individual differences in human beings will be; the more inductive the cognition is, the smaller the individual differences of human beings will be [12].

Since nonverbal cues play a powerful role in individual cognition [15], these different cognitive dimensions can often be associated with different cultural landscapes. People with sensual thinking tend to like the natural and original landscape; people with intellectual cognition tend to prefer an orderly and easily identifiable environment, and; people with rational cognition tend to like landscapes with cultural symbols. Thus, with regards to the riverine landscape, different people will inevitably 
focus on different cognitive styles, leading to different cognitive outcomes. These cognitive results can be interpreted through the representation of the SOP. The SOP is an important indicator to measure the relationship between people and the environment in a geographical space. It is often evaluated through two dimensions: place dependence and place attachment. The stronger the SOP is, the closer and more positive the relationship between people and the environment in the region will be.

Based on the above analysis, this study initially divided people's cognition of the riverine landscape into three dimensions: sensual cognition, intellectual cognition, and rational cognition. Given the difficulty in measuring inductive cognition, this study merged it with sensual cognition. A conceptual model of the relationship between the three cognitive dimensions and the SOP of a riverfront space was constructed, and a conceptual structural model regarding the dimensions of cognition and SOP was established by using the SEM shown in Figure 1. The following three hypotheses were proposed to verify the relationship and strength between the cognitive and SOP dimensions.

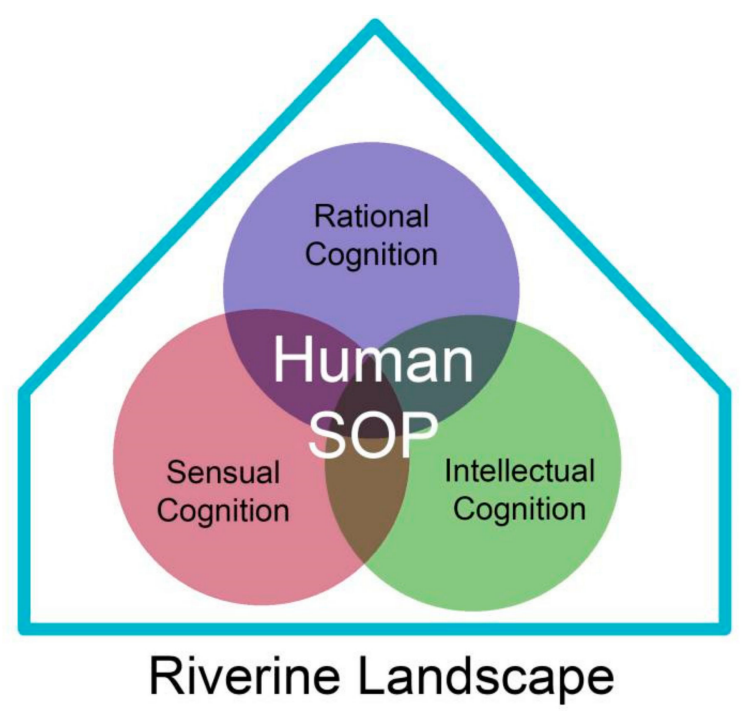

(a) Conceptual Model

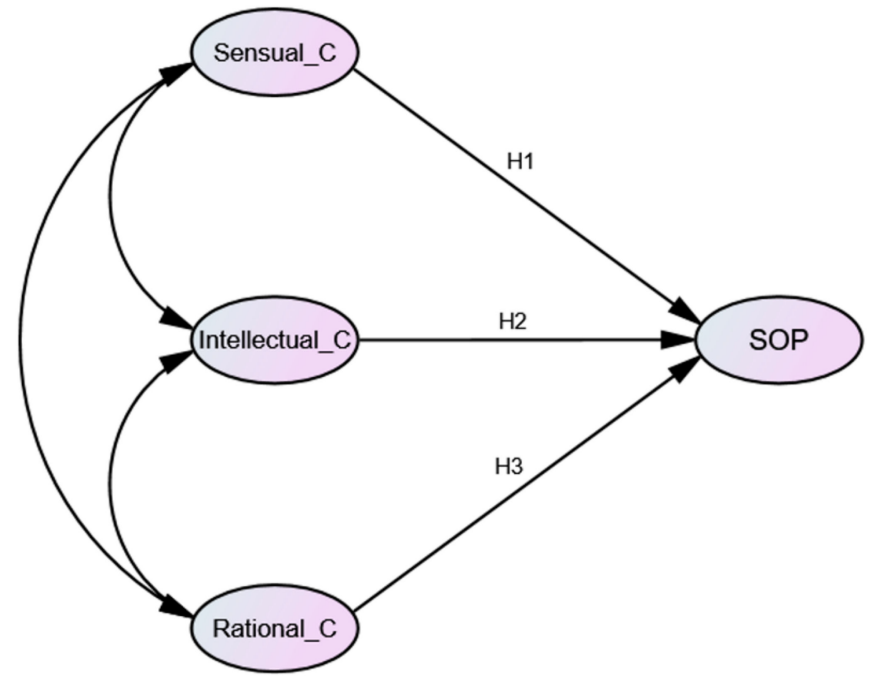

(b) Conceptual Structural Model

Figure 1. Conceptual Model and Conceptual Structural Model.

Hypothesis 1. People's sensual cognition of a riverine landscape has a relevant influence on their sense of place of a riverfront park. 
Hypothesis 2. People's intellectual cognition of a riverine landscape has a relevant influence on their sense of place of a riverfront park.

Hypothesis 3. People's rational cognition of a riverine landscape has a relevant influence on their sense of place of a riverfront park.

\subsection{Research Method}

The relevant indicators of cognition and the SOP could not be obtained by direct measurements. Therefore, after determining the theoretical model and research hypotheses, this study selected an SEM suitable for assessing latent variables. In addition, operational definitions were assigned to the three cognitive dimensions to facilitate the establishment of specific measurement models. Sensual Cognition refers to the visitor's overall impression of the riverine landscape. Intellectual Cognition refers to the visitor's classification and identification of the riverine landscape. Rational Cognition refers to visitor's association cognition of the riverine landscape.

Based on the operational definition of these three dimensions, and combined with the characteristics of the riverine landscape, a measurement scale (Table 1) was established. The scale consisted of 37 questions that collected the respondent's personal information, their perception of the water body, and their SOP of the park. The questions regarding the SOP were quoted from Chen (2015) and Williams (2003) [16,17], and the remaining exploratory questions were developed by individuals based on the definition of the cognition of the riverine landscape. All cognitive questions and questions regarding the SOP used the Likert 7 scale, ranging from strongly disagree to strongly agree [18].

Finally, according to the three dimensions (the typical characteristics of the natural rivers in the riverfront space, the diversity of the people in the area, and the diversity of human-river interactions), a typical representative riverfront park was selected as the research area, and the subject's data were obtained through questionnaires. After performing reliability and validity tests, the corresponding measurement data involved in the verification was adjusted, and the structural empirical model was used for relevant empirical analysis. 
Table 1. Measurement items.

\begin{tabular}{|c|c|c|c|}
\hline Latent Factors & Observed Variables & Items & Sources \\
\hline \multirow{6}{*}{$\begin{array}{c}\text { Sense of Place (SOP) } \\
\text { (Identity) }\end{array}$} & PI_1 & I think this is already part of my life. & \multirow{12}{*}{$\begin{array}{c}\text { [16] Measurement and } \\
\text { Application of Place } \\
\text { Attachment Scale in } \\
\text { Urban Park }\end{array}$} \\
\hline & PI_2 & This place has a special meaning for me. & \\
\hline & PI_3 & I really agree with this place. & \\
\hline & PI_4 & $I^{\prime} m$ very attached here. & \\
\hline & PI_5 & It's very much to my liking to visit here. & \\
\hline & PI_6 & It's very important to me. & \\
\hline \multirow{6}{*}{$\begin{array}{c}\text { Sense of Place } \\
\quad \text { (SOP) } \\
\text { (Dependence) }\end{array}$} & PD_1 & This is the best place for my leisure and entertainment. & \\
\hline & PD_2 & There's no other place in my heart that can be compared with this place. & \\
\hline & PD_3 & I get more satisfaction here than anywhere else. & \\
\hline & PD_4 & For me, recreation here is more important than anywhere else. & \\
\hline & PD_5 & It's almost as much fun here as anywhere else. & \\
\hline & PD_6 & I like to have fun here and would not go anywhere else. & \\
\hline \multirow{6}{*}{ Sensual Cognition } & SC_1 & I think Yihu Lake Park is very shallow & \multirow{6}{*}{ Self-developed } \\
\hline & SC_2 & I think the water from Yihu Lake Park is of good quality. & \\
\hline & SC_3 & I think the time during riverfront activities in Yihu Lake Park passes by very slowly. & \\
\hline & SC_4 & I think the cultural atmosphere of the riverine landscape in Yihu Lake is very strong. & \\
\hline & SC_5 & I think the water features of Yihu Lake Park are well maintained. & \\
\hline & SC_6 & I find it very easy to get into the river or lake in Yihu Lake Park. & \\
\hline \multirow{5}{*}{ Intellectual Cognition } & PC_1 & I know I can visit the water island in Yihu Lake Park. & \multirow{5}{*}{ Self-developed } \\
\hline & PC_2 & I know there is a lot of falling water in Yihu Lake Park. & \\
\hline & $\begin{array}{l}\text { PC_3 } \\
\text { PC_4 }\end{array}$ & $\begin{array}{l}\text { I know exactly where the water from Yihu Lake Park comes from and where it flows. } \\
\text { I know exactly where the water scenery is the most beautiful in Yihu Lake Park. }\end{array}$ & \\
\hline & PC_5 & I know very well the best places where we can play with water in Yihu Lake Park. & \\
\hline & PC_6 & I know exactly where the coolest place is by the water in Yihu Lake Park. & \\
\hline \multirow{7}{*}{ Rational Cognition } & RC_1 & I know how long it takes to walk around the lake in the middle of Yihu Lake Park. & \multirow{7}{*}{ Self-developed } \\
\hline & RC_2 & I know a lot of interesting stories that happened in Yihu Lake Park. & \\
\hline & RC_3 & If I have something important that I can't figure out, I would be happy to think about it & \\
\hline & RC_4 & It's good for my health to visit Yihu Lake Park often. & \\
\hline & RC_5 & I'm aware of what activities are not allowed in Yihu Lake Park. & \\
\hline & RC_6 & I'm well aware of the history regarding the construction of Yihu Lake Park. & \\
\hline & RC_7 & I can think of a lot of things from the words, images and signs in Yihu Lake Park. & \\
\hline
\end{tabular}




\section{Data Description and Model Testing}

\subsection{The Case Study Area}

The area selected for this study was Yihu Lake Park. The park is located in Du-Jiangyan City. Dujiangyan is famous for its historic irrigation project and its proximity to the ancient capital of Chengdu. It also contains world-famous natural and cultural heritage sites. Dujiangyan represents the history of China's water management from the Qin Dynasty more than 2000 years ago, and it is also a typical representative of China's cultural heritage of water today. Based on the needs of regional ecological protection and the protection of historical and cultural heritage, the development of water resources in a high-intensive manner is prohibited, but people can have easy access to high-quality water. The development of the city and the rivers are well-balanced, which allows for research into the dual impact of nature and humanity.

Yihu Lake Park is the largest open riverfront park in the city and is adjacent to Puyang River, which is a tributary of the Min River and one of the most important irrigation rivers in the Chengdu Plain. Yihu Lake Park was built after the 2008 Wenchuan Earthquake and serves more than 20,000 residents in the surrounding areas. Water was diverted from the upper reaches of the Puyang River into the park, and a large pit was excavated in the centre of the park to form a large artificial lake (named Yihu) with the excess water flowing into the Puyang River through the downstream channel. The park has a large area for interaction with water and includes a beautiful lake, river beach, waterfront trails, riverbanks, lawns, squares, and car campsites. It has become the most popular destination for riverfront recreation. Compared with other urban riverfront parks, Yihu Lake Park has a larger amount of water and more diverse forms of flowing water. There are a variety of spaces for interaction with water. For instance, people can swim and row in the lake, relax near the lake on the riverside lawn and square, walk around the lake, play with sand on the beach of the Puyang River, photograph the layered waterfall, and participate in creative activities such as drawing. The nature of the river, the diversity of people who enjoy themselves there, and the diversity of human-river interactions have shaped the rich riverine landscape of Yihu Lake Park. The park's formal and informal activities for interaction with water have also given this riverfront park a unique SOP (Figure 2).

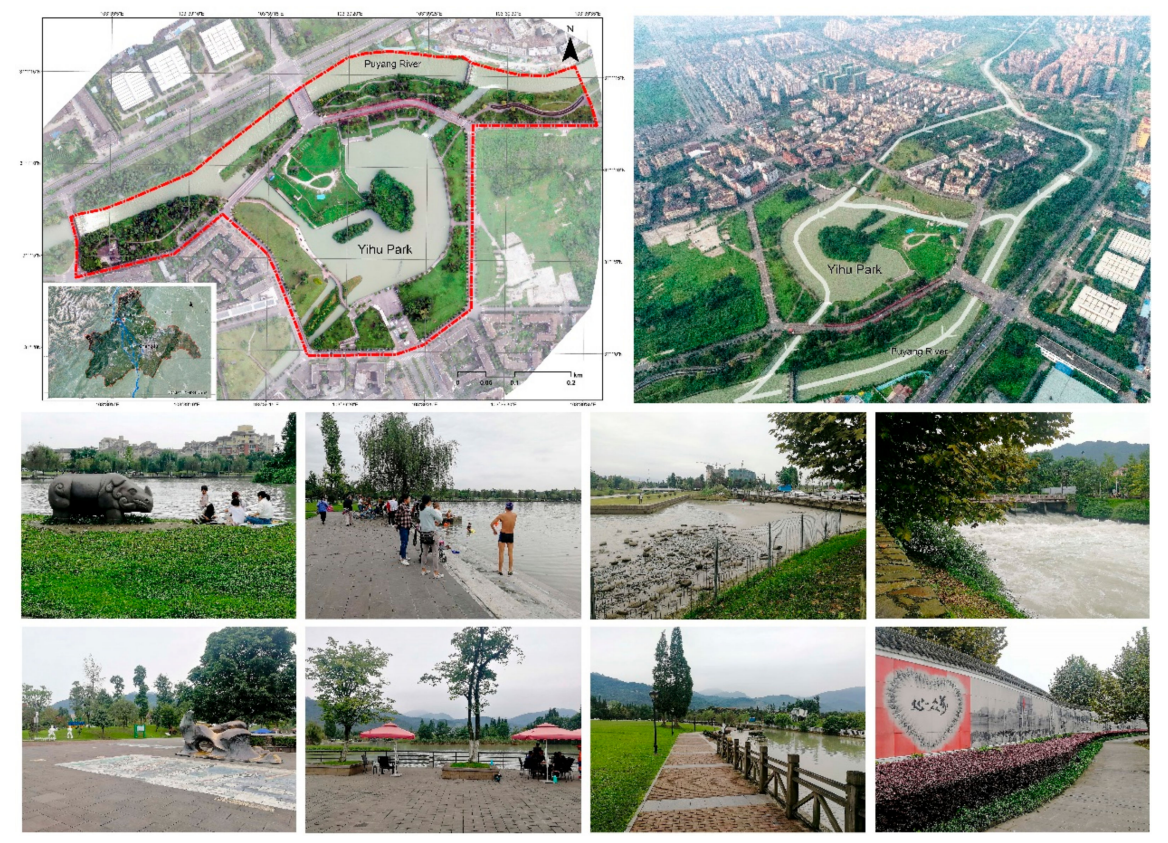

Figure 2. Images of Yihu Park and Puyang River. 


\subsection{Data Collection and Statistical Analyses}

During 10-17 June 2019, the research team distributed questionnaires to 509 park visitors through accidental sampling in Yihu Lake Park. Among those who received the questionnaires, 363 responded and 146 people did not complete the questionnaire ( $71.3 \%$ response rate). There were 329 valid questionnaires, and the demographic information is shown in Table 2.

Table 2. Respondent profile.

\begin{tabular}{cccc}
\hline $\begin{array}{c}\text { Respondents' } \\
\text { Characteristics }\end{array}$ & Item & Frequency (n = 329) & Percentage (\%) \\
\hline \multirow{2}{*}{ Gender } & Male & 128 & 38.9 \\
& Female & 201 & 61.1 \\
\hline \multirow{2}{*}{ Age } & $6-22$ & 103 & 31.3 \\
& $23-60$ & 193 & 58.7 \\
& $61-80$ & 26 & 7.9 \\
& over 80 & 7 & 2.1 \\
\hline \multirow{2}{*}{ Place of residence } & Surrounding residential areas & 69 & 21.0 \\
& Dujiangyan downtown area & 165 & 50.2 \\
& (Non-surrounding residential areas) & & 14.3 \\
& Dujiangyan township & 47 & 14.6 \\
\hline How often do I come to & (Outside the downtown area) & 48 & 16.4 \\
this park? & Outside Dujiangyan & 54 & 15.2 \\
& At least once a day & 50 & 18.2 \\
& Several times a week & 60 & 15.8 \\
& Once a week & 52 & 18.8 \\
& Once a month & 62 & 6.1 \\
& Several times a year & 20 & 9.4 \\
\hline Hove I ever played in the & Once a year & 31 & 5.8 \\
water of Yihu Lake Park? & First time here & 19 & 10.9 \\
\hline & Very unfamiliar & 36 & 7.6 \\
How familiar am I with & Less familiar & 25 & 21.9 \\
this park? & A little unfamiliar & 72 & 14.6 \\
& General & 48 & 23.1 \\
& A little familiar & 76 & 16.1 \\
\hline & More familiar & 53 & 76.3 \\
\hline & Very familiar & 78 &
\end{tabular}

The ratio of the observation variables to the number of samples in this study model was 1:10.6, which is in line with the requirements of 1:10 for a general SEM model analysis [19].

\subsection{SEM Testing}

Confirmatory Factor Analysis (CFA) is an important step before conducting SEM analysis. Thompson (2004) proposed that the measurement model should be analysed first. The present study first optimised the measurement model and the structural model by testing the reliability, convergent validity, and discriminant validity to obtain more accurate results.

\subsubsection{Testing of Reliability and Convergent Validity}

This study tested the reliability and convergent validity of each dimension by establishing measurement models (Figure 3). After the test, the questions for the SOP dimension with factor loading below 0.6 were excluded. Because the other three dimensions were self-developed exploratory questions, those with a factor loading below 0.5 were excluded. After comparing and analysing the indicators used to test the fitness of the proposed model, some questions with large residuals were removed. 

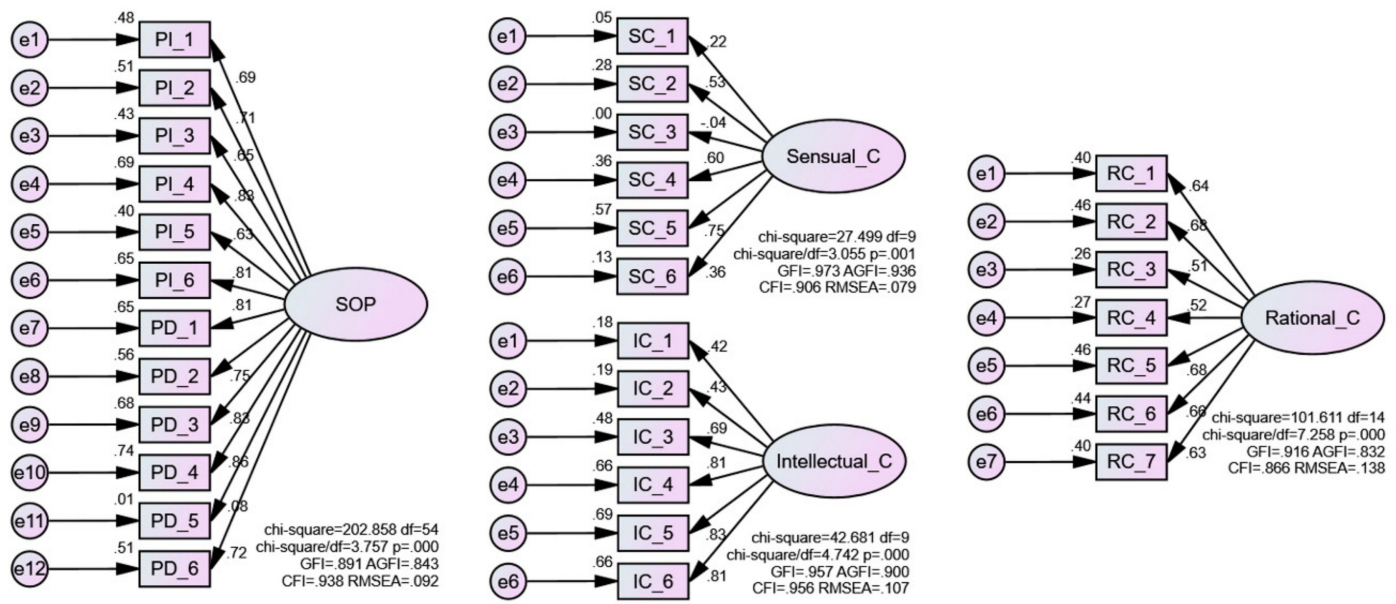

Figure 3. Measurement model.

The results show that after adjustment, the standardised factor loading (Std.) of the four dimensions were between 0.521 and 8.54 , thus reaching significance level. The composite reliability (CR) was between 0.751 and 0.899 , and the average variance extracted (AVE) was between 0.407 and 0.678. These results were in line with the standards from Hair et al. and Fornell and Larcker [20]. The following results were observed: (1) The factor loading was greater than 0.5 ; (2) the composite reliability was greater than 0.6 ; (3) the AVE was greater than 0.5 . The model met the requirements of the criteria, except for the value of the sensual dimension, which was slightly below 0.5 , but within an acceptable range between 0.36 and 0.5 . Therefore, all four dimensions had appropriate reliability and convergent validity and were in line with the requirements for analysis and research. The questions and test results are shown in Table 3.

Table 3. Reliability and validity.

\begin{tabular}{|c|c|c|c|c|c|c|c|c|c|}
\hline Factor & Item & Unstd. & S.E. & T-value & $P$ & Std. & SMC & C.R. & AVE \\
\hline $\begin{array}{c}\text { Acceptable } \\
\text { Reference Value }\end{array}$ & & & & & $<0.05$ & $>0.5$ & $>0.25$ & $>0.7$ & $>0.36$ \\
\hline \multirow{7}{*}{ SOP } & PI_1 & 1.000 & & & & 0.713 & 0.508 & 0.899 & 0.561 \\
\hline & PI_2 & 1.040 & 0.082 & 12.749 & $* * *$ & 0.740 & 0.548 & & \\
\hline & PI_4 & 1.166 & 0.080 & 14.656 & $* * *$ & 0.854 & 0.729 & & \\
\hline & PI_5 & 0.676 & 0.061 & 11.113 & $* * *$ & 0.644 & 0.415 & & \\
\hline & PI_6 & 1.104 & 0.077 & 14.309 & $* * *$ & 0.833 & 0.694 & & \\
\hline & PD_1 & 1.126 & 0.084 & 13.462 & $* * *$ & 0.782 & 0.612 & & \\
\hline & PD_6 & 0.878 & 0.078 & 11.240 & $* * *$ & 0.651 & 0.424 & & \\
\hline \multirow{3}{*}{ Sensual_C } & SC_2 & 1.000 & & & & 0.521 & 0.271 & 0.771 & 0.407 \\
\hline & SC_4 & 1.077 & 0.163 & 6.588 & $* * *$ & 0.591 & 0.349 & & \\
\hline & SC_5 & 1.214 & 0.207 & 5.853 & $* * *$ & 0.776 & 0.602 & & \\
\hline \multirow{3}{*}{ Intellectual_C } & IC_4 & 1.000 & & & & 0.793 & 0.271 & 0.863 & 0.678 \\
\hline & IC_5 & 1.081 & 0.072 & 15.085 & $* * *$ & 0.836 & 0.349 & & \\
\hline & IC_6 & 1.108 & 0.073 & 15.113 & $* * *$ & 0.840 & 0.602 & & \\
\hline \multirow{3}{*}{ Rational_C } & RC_5 & 1.000 & & & & 0.795 & 0.632 & 0.751 & 0.505 \\
\hline & RC_6 & 0.933 & 0.105 & 8.868 & $* * *$ & 0.730 & 0.533 & & \\
\hline & RC_7 & 0.681 & 0.080 & 8.462 & $* * *$ & 0.591 & 0.349 & & \\
\hline
\end{tabular}

Note: ${ }^{* * *} p<0.001$; Unstd. refers to Unstandardized estimates; S.E. refers to Standard error; Std. refers to Standardized estimates.

\subsubsection{Discriminant Validity Testing}

Discriminant validity analysis was used to verify whether there were statistical differences between two different dimension correlations. In this study, the implied correlations (for all variables) of four dimensions were calculated using correlation analysis of the structural model and the discriminant validity was tested based on the square root of the AVE of each dimension. Overall, the results showed good discriminant validity between the four dimensions (Table 4). 
Table 4. Results of discriminant validity measures.

\begin{tabular}{cccccc}
\hline Factor & AVE & SOP & Rational_C & Intellectual_C & Sensual_C \\
\hline SOP & 0.561 & $0.749^{*}$ & 0.616 & 0.653 & 0.511 \\
Rational_C & 0.505 & 0.616 & $0.711^{*}$ & 0.735 & 0.462 \\
Intellectual_C & 0.678 & 0.653 & 0.735 & $0.823^{*}$ & 0.400 \\
Sensual_C & 0.407 & 0.511 & 0.462 & 0.400 & $0.638^{*}$ \\
\hline
\end{tabular}

* Represent the square of average variance.

\section{Results}

With the aid of AMOS 24.0, the maximum likelihood estimate (MLE) method in the SEM was used to validate the hypotheses and the fitness between the proposed model and the collected data. The fitness of the proposed model was revealed by the indices of the ratio of the Chi-square and degrees of freedom $\left(\chi^{2} / \mathrm{df}\right)$, goodness-of-fit (GIF), adjusted goodness-of-fit index (AGFI), the comparative fit index (CFI), root-mean-square error approximation (RMSEA), and standardised root mean square residual (SRMR). The recommended criteria of a goodness-of-fit and the values of these indices are shown in Table 5. All of the indices met the recommended fitted values [21].

Table 5. Evaluation of the overall fitness of the conceptual model.

\begin{tabular}{ccc}
\hline Fitness Index & Reference Value & Value \\
\hline Chi-square $\left(\chi^{2}\right)$ & & 167.689 \\
degrees of freedom(df) & & 98.000 \\
$\chi^{2} /$ df ratio & $<3$ & 1.711 \\
GFI & $\geq 0.9$ & 0.940 \\
AGFI & $\geq 0.9$ & 0.916 \\
CFI & $\geq 0.9$ & 0.971 \\
RMSEA & $<0.08$ & 0.470 \\
SRMR & $<0.005$ & 0.038 \\
\hline
\end{tabular}

A path analysis was then performed to test the hypotheses. From the non-standardised results, all residuals were positive and significant and violation statistics passed the test. From the standardised results, the factor loading of the questions for measurement was between $0.52-0.85$, which was in line with the suggested value of 0.5 or above in the exploratory questionnaire. The SMC of the measurement model was between 0.27 and 0.72 , which was acceptable. The explanatory force $\mathrm{R}^{2}$ of the SOP from the three dimensions was 0.52 , which was ideal (Figure 4).

The results in Table 6 shows that the three hypotheses were supported. Intellectual cognition (Intellectual_C) had the most significantly positive impact on SOP (Std. $=0.401, \mathrm{t}=4.397, p<0.001$ ). Sensual cognition (Sensual_C) also had a significantly positive impact on SOP (Std. $=0.256, t=3.550$, $p<0.001$ ), indicating that $\mathrm{H} 1$ was supported. Furthermore, rational cognition (Rational_C) still had a significantly positive impact on SOP (Std. $=0.203, \mathrm{t}=2.056, p<0.05)$.

Table 6. Results of the tested hypotheses.

\begin{tabular}{ccccccc}
\hline Hypothesis & Relationship & Std. & S.E. & T-value & $\boldsymbol{P}$ & Results \\
\hline H1 & Sensual_C $\rightarrow$ SOP & 0.256 & 0.131 & 3.550 & $* * *$ & Supported \\
H2 & Intellectual_C $\rightarrow$ SOP & 0.401 & 0.084 & 4.397 & $* * *$ & Supported \\
H3 & Rational_C $\rightarrow$ SOP & 0.203 & 0.096 & 2.056 & 0.040 & Supported \\
\hline
\end{tabular}




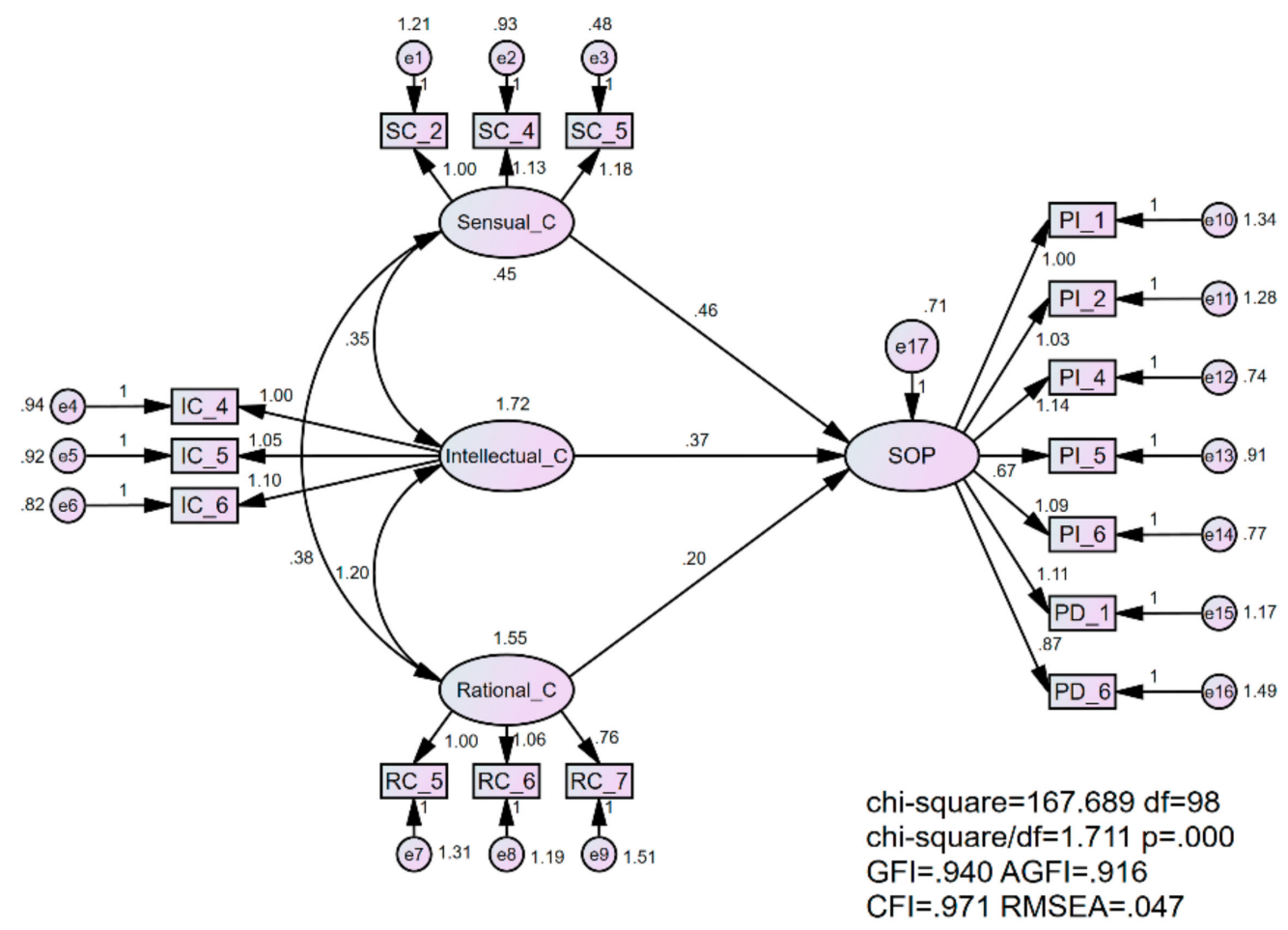

(a)

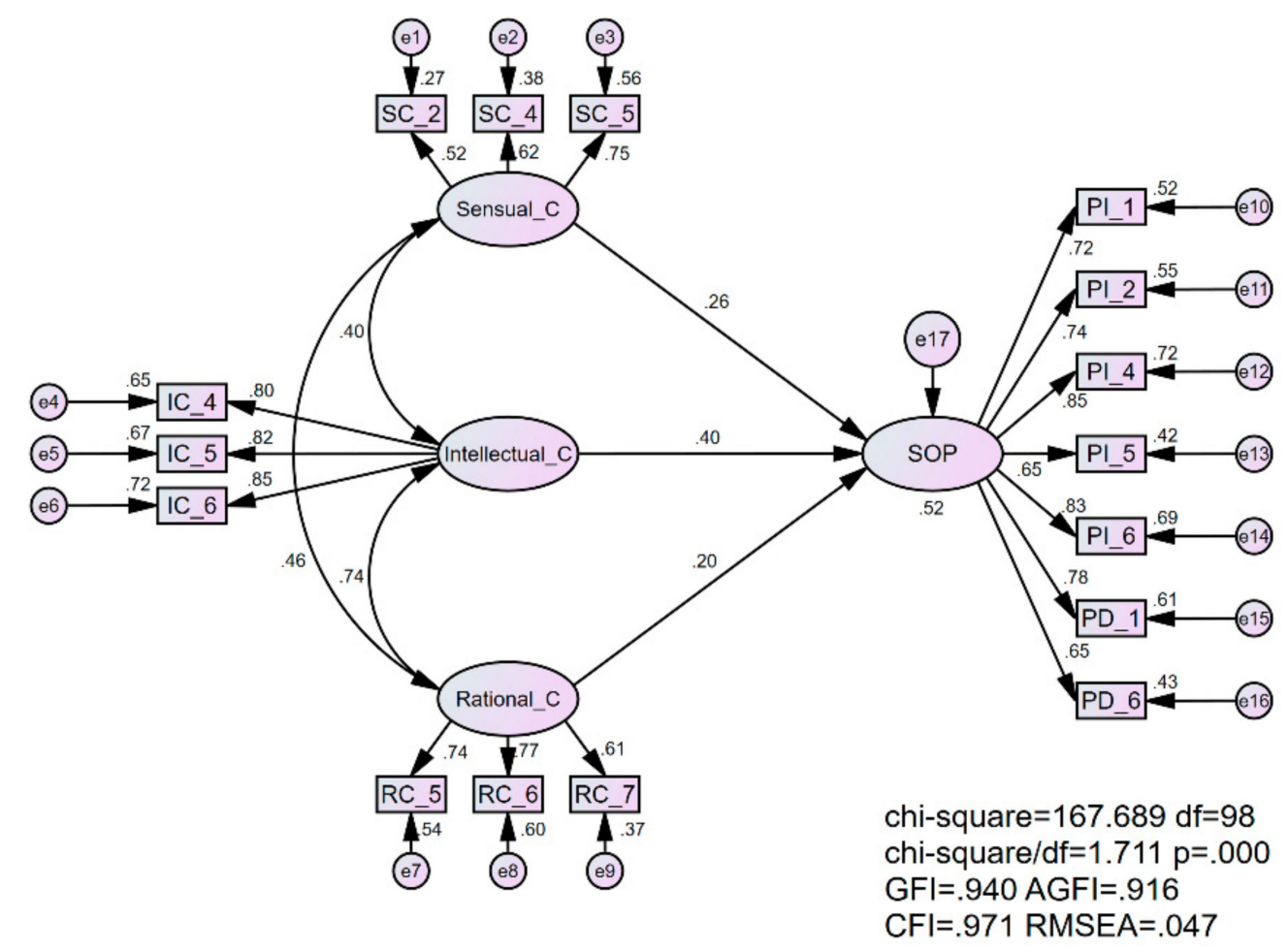

(b)

Figure 4. Un-standardised estimates (a) and standardised estimates (b). 


\section{Discussion}

This research explored the construction of a new theoretical model, which provided useful information using SEM analysis. Quantitative analysis of the SEM was able to clearly define people's cognitive differences in the urban riverine landscape, and it was shown to have a significant influence on the formation of the SOP at varying degrees. From the perspective of the model-construction process and under the guidance of cognitive theory and the theories related to the SOP, the overall conceptual model structure was relatively simple, which clearly reflected the relationship between different cognitive dimensions and the SOP. The SEM used could address cognitive measurement and statistical analysis of the riverine landscape through the analysis of latent variables. One of the main issues in model construction is the design of the questionnaire for collecting measurements. The scales of the three cognitive dimensions in this study were different from a traditional measurement questionnaire constructed from the overall perception level. It was a self-developed questionnaire specifically designed to assess the riverine landscape and to measure the operational definitions from the cognitive dimension of a riverfront park. Because the questionnaire regarding the SOP was well established, this study selected Chen's measurement questionnaire for the SOP in the park as the reference [16]. Based on the SOP study of parks by Williams and Vaske [17], the measurement questionnaire used in the present study was a localised questionnaire designed to measure the characteristics of Chinese parks that provided reliable and valid data. From the reliability, convergent validity and discriminant validity analyses of the measurement model, we identified that the factor loading and the convergent validity of the self-developed measurement questions were partially acceptable. Thus, three out of the six questions were retained. Since the questions relevant to the SOP were cited, their overall reliability and validity were higher. However, five questions to measure place dependence were removed, according to the principle of preference. In addition, the discriminant validity between the intellectual dimension and the rational dimension was not ideal. Therefore, in future studies, relevant scales can be optimised to lay a more solid foundation for further research.

From the results of the model analysis, the three research hypotheses were significantly related. Among them, the standardised path coefficient of intellectual cognition was the highest (0.401), which was different from our general sense of cognition. Generally, people consider the most important influence on the formation of the SOP should be the sensual cognition based on emotional and aesthetic factors. However, from the results of this analysis, the influence of sensual cognition was not the highest. Rather, there was a large difference between sensual cognition and intellectual cognition. This shows that in this case study, the higher a person's intellectual cognition of a riverine landscape is, the easier it is to form a stronger SOP. On the other hand, since the research area was a park with a relatively balanced natural and artificial environment, new hypotheses can be further proposed: (1) For the riverfront parks dominated by natural and ecological environment, the sensual cognition based on the function of integrating senses and emotions is most important for the formation of the SOP; (2) for parks where the natural environment and the artificial environment are integrated, the intellectual cognition based on the function of distinction is most important for the formation of the SOP; (3) for parks with historical and cultural significance or dominated by artificial environment, the rational cognition based on the function of connectivity is more important for the formation of the SOP. An empirical analysis could be conducted to discuss and analyse the above-proposed hypotheses.

From the perspective of the sustainable development of rivers, especially that of urban rivers, it is very important to conduct an in-depth investigation of the cognitive dimension of the riverine landscape. Firstly, the external environment can be attributed to the influence of the three cognitive dimensions on human psychology. Secondly, people's cognition of rivers will change over time, but the cognitive dimension is relatively stable. Therefore, studying the riverine landscape requires careful consideration of the differences between different cognitive dimensions. For example, the riverfront parks with green trees may seem ecological and natural from the sensual cognition, but the same green space everywhere can be monotonous and lacks spatial division, thereby reducing the quality of intellectual cognition. In addition, the lack of river information signs, memorial sculptures about 
historical stories, iconic bridges, and guiding signs can reduce the quality of rational cognition. With this in mind, we can enhance the riverine landscape through scientific planning and design of the riverfront space. The focus is on the improvement of the riverine landscape related to intellectual cognition, such as diverse spaces for interaction with water, diversified water features, and the strengthening of the characteristics of different landscapes, thereby greatly promoting the formation of the SOP of the river. The stronger the SOP that people have of the river, the stronger the place attachment and place dependence people will establish on the river and riverfront space. This will facilitate a more enjoyable experience for people to interact with the river.

\section{Conclusions}

In this study, the research on the SOP of urban riverfront space was extended from the riverine landscape to riverine landscape cognition. The relationship between different cognitive dimensions of the riverine landscape and the SOP of the riverside space was further explored. This study used the SEM to develop a measurement model of three cognitive dimensions (sensual cognition, intellectual cognition, and rational cognition) and obtained quantitative results on the influence of the three cognitive dimensions on the SOP in a riverfront park. This was achieved from assessing the cognitive dimension of the riverine landscape and combined it with cognitive theory and theories related to the SOP in the riverfront space. The results showed that the SEM had a good degree of fit, and the statistical results of the three hypotheses were all significant. The hypothesis was not rejected; therefore, the theoretical model was established.

The results of Hypothesis 1 indicated that sensual cognition had a significant impact on the SOP of the riverfront park (Std. $=0.256$; Table 6 ). Therefore, the riverine landscape needs to be considered in the planning and design of waterfront parks to form a unified sensual cognitive effect. For example, the overall colour matching, the coordination of landscape and greening, and the balance of form and proportion all need to be considered in the park planning and design.

The results of Hypothesis 2 showed that intellectual cognition had the greatest influence on the SOP of the riverfront park (Std. $=0.401$; Table 6). As such, there should be a focus on designing riverine landscapes that enhance intellectual cognition. For example, the traditional Chinese approach of displaying different scenes with the moving of steps; strengthening the changes between opening and closing or twists and turns of water space; or adding multi-level changes in the shoreline design of urban riverfront space and distinguishing different water functional areas.

The results of Hypothesis 3 showed that rational cognition had a slightly lower impact on the SOP of the riverfront park $($ Std. $=0.203$; Table 6 ). Therefore, we should focus on designing riverine landscapes that are easy to establish associations with, such as road signs leading to the water space, water sculptures, iconic bridges, and other facilities.

We should actively apply the results of the three hypotheses to improve the riverine landscape quality through planning and design. Guidance can be provided from the following three aspects: the riverfront vegetation and riverine landscape, the riverfront road and square landscape, and the riverfront architectural and symbolic landscape. The riverfront vegetation landscape emphasises the dimension of sensual cognition, which aims to enhance the overall image of large-scale greening and waterscape from the aspects of colour aesthetics and morphological aesthetics, and harmoniously integrates the information felt by the five senses. The design of the riverfront road and square landscape focuses on the dimension of intellectual cognition, intending to improve the identification of riverfront space from the perspective of using functions so that visitors can easily identify where and what type of activity is appropriate to interact with water. The riverfront architectural and symbolic landscape emphasises the dimension of rational cognition, with a focus on the associative function of the riverfront space in terms of history, culture and space orientation, such as setting up landscaped pier buildings, local representative aquatic animal sculptures, and park-oriented signs. Through the planning guidance in different dimensions, we can better enhance visitors' local attachment and local identity to the urban riverfront space. 
The limitations of this study need to be strengthened in any subsequent studies. Firstly, the measurement model of cognitive dimensions needs to be optimised. The number of self-developed questions of the measurement models was insufficient, and the factor loading of some questions was not high enough. As such, there is some scope for optimisation and improvement of reliability and validity. Secondly, the research object is still relatively simple. In subsequent studies, multiple typical research areas can be selected for a comparative study of multiple groups to further strengthen the empirical results. Thirdly, the object of this study was of people's cognition of the riverine landscape. In theory, this cognitive model can be applied to all cultural landscapes, but this remains to be tested by further research. Fourthly, this is a case study relevant to a typical park in a riverfront space. For subsequent research, more typical cases of urban riverfront spaces need to be analysed to further verify the theoretical model.

In summary, the study of human-river interactions should not only concern the natural law of the external environment but also explore the inherent law of how the riverfront environment and people's cognitive activities are best matched with each other. The models of the multiple cognitive dimensions of riverine landscape and the SOP constructed in this study could explain the related laws of human cognition of riverine landscape in the process of human-river interaction. The models also provided a new perspective on the theoretical investigation of the SOP of rivers and the planning and design practice of the riverfront space. In the future, we plan to further optimise the survey questionnaires, locate more typical urban riverfront spaces for investigation, and apply the theory to riverfront space development projects. It is expected that more effective and scientific guidance can be provided for the sustainable interaction between people and rivers from the perspective of cognitive science.

Author Contributions: Conceptualization, L.-Q.Z. and W.D.; Methodology, L.-Q.Z. and W.D.; Software, L.-Q.Z.; Validation: J.Y.; Formal Analysis, L.-Q.Z.; Investigation, L.-Q.Z. and X.-H.T.; Resources, W.D; Data Curation, L.-Q.Z., J.Y. and X.-H.T.; Writing Original Draft Preparation, L.Z; Writing Review \& Editing, L.-Q.Z., J.Y., X.-H.T. and W.D; Visualization, L.-Q.Z.; Supervision, W.D.; Project Administration, W.D.; Funding Acquisition, W.D. All authors have read and agreed to the published version of the manuscript.

Funding: This research was funded by [the Science and Technology Service Network Initiative] grant number [KFJ-STS-QYZD-060] And The APC was funded by [the Science and Technology Service Network Initiative ].

Acknowledgments: The authors are greatly thankful to the anonymous reviewers for their valuable comments. In addition, we wish to thank the students from Sichuan Agricultural University who participated in the survey and the kind local visitors who were willing to be interviewed. The students are Liang Li, Zhi-hong Xu, Zhen-ya Chen, Yu Guo, Kai-li Zhang, Li-juan Huang, Jia Li, Yu-qi Deng, Xue Wang, and Man-ni Yang.

Conflicts of Interest: The authors declare no conflicts of interest.

\section{References}

1. Xu, H.S.; Zheng, H.; Chen, X.S.; Ren, Y.F.; Ouyang, Z.Y. Relationships between river water quality and landscape factors in Haihe River Basin, China: Implications for environmental management. Chin. Geogr. Sci. 2016, 26, 197-207. [CrossRef]

2. Sheng, J.; Dai, S.Z.; Zhang, Z.H. Waterfront Landscape Design in Oasis City: The Landscape Design for Yili Islands Design. Planners 2017, 33, 120-126.

3. Yin, B.H.; Yang, M. Discussion of the River Landscape Planning in Long-term Planning's Land Use-Take the Concept Plan of Wangfu River as an Example. Landsc. Archit. 2018, 2018, 56-60.

4. Qiao, J.Y.; Wang, M.; Zhang, D.Q.; Ding, C.Y.; Wang, J.J.; Xu, D.W. Synergetic Development Assessment of Urban River System Landscapes. Ssutainability 2017, 9, 1-15.

5. Lu, M.; Wen, C.Y.; Wang, C.Y. Landscape Design of River Channels in Small Towns based on Regional Culture-Case Study of Landscape Design of Duohua River. In Matec Web of Conferences; E D P Sciences: 17 Ave Du Hoggar Parc D Activites Coutaboeuf Bp 112, F-91944; Cedex: Paris, France, 2018; Volume 206, pp. 150-155.

6. Shi, S.H.; Kondolf, G.; Li, D.H. Urban River Transformation and the Landscape Garden City Movement in China. Sustainability 2018, 10, 4103. [CrossRef] 
7. Davenport, M.A.; Anderson, D.H. Getting From Sense of Place to Place-Based Management: An Interpretive Investigation of Place Meanings and Perceptions of Landscape Change. Soc. Nat. Resour. 2005, 7, 625-641. [CrossRef]

8. Kim, M. Influence of Perceptual Range on Human Perceived Restoration. Sustainability 2018, 10, 3139. [CrossRef]

9. Bricker, K.S.; Kerste, D.L. Level of Specialization and Place Attachment: An Exploratory Study of Whitewater Recreationists. Leis. Sci. 2010, 22, 233-257.

10. Verbrugge, L.; Buchecker, M.; Garcia, X.; Gottwald, S.; Muller, S.; Praestholm, S.; Olafsson, A.S. Integrating sense of place in planning and management of multifunctional river landscapes: Experiences from five European case studies. Sustain. Sci. 2019, 14, 669-680. [CrossRef]

11. Kant, L. Critique of Pure Reason; World Book Inc.: Beijing, China, 2016; pp. 151-152.

12. Wang, D.Y. General Theory of Material Evolution-The Unified Philosophical Principles of Natural Existence, Spiritual Existence and Social ESxistence; China CITIC Press: Beijing, China, 2015; pp. 99-117.

13. Hawking, S.W. The Grand Design; Bantam Books: London, UK, 2011; pp. 56-58.

14. Chariker, L.; Shapley, R.; Young, L.S. Orientation Selectivity from Very Sparse LGN Inputs in a Comprehensive Model of Macaque V1 Cortex. J. Neurosci. 2016, 49, 12368-12384. [CrossRef] [PubMed]

15. Michael, S.G.; Richard, B.L.; George, R.M. Cognitive Neuroscience; China Light Industry Press Ltd.: Beijing, China, 2018; pp. 87-90.

16. Chen, H.; Xiao, L. Measurement and Application of Place Attchment Scale in Urban Park. J. South Norm. Univ. (Nat. Sci. Ed.) 2015, 47, 140-146.

17. Williams, D.R.; Vaske, J.J. The Measurement of Place Attachment: Validity and Generalizability of a Psychometric Approcah. For. Sci. 2003, 49, 830-840.

18. Brown, J.D. Likert items and scales of measurement? SHIKEN JALT Test. Eval. SIG Newsl. 2011, 15, 10-14.

19. Anderson, R.E.; Black, W.C.; Hair, R.L. Multivariate Data Analysis; Prentice-Hall: London, UK, 1998; p. 34.

20. Fornell, C.; Larcker, D.F. Evaluating Structural Equation Models with Unobservable Variables and Measurement Error. J. Mark. Res. 1981, 18, 39-50. [CrossRef]

21. Iacobucci, D. Structural Equations Modeling: Fit Indices, Sample Size and Advanced Topics. J. Consum. Psychol. 2010, 20, 90-98. [CrossRef]

(C) 2019 by the authors. Licensee MDPI, Basel, Switzerland. This article is an open access article distributed under the terms and conditions of the Creative Commons Attribution (CC BY) license (http://creativecommons.org/licenses/by/4.0/). 